\title{
Dermatology
}

Dermatology 2009;218:176-177

DOI: $\underline{10.1159 / 000182271}$

\section{Fox-Fordyce Disease in Daughter and Father}

L. Scroggins, E. Kelly, B. Kelly

University of Texas Medical Branch, Galveston, Tex., USA

Key Words

Fox-Fordyce disease $\cdot$ Apocrine miliaria

\section{Introduction}

Fox-Fordyce disease (apocrine miliaria) is an uncommon condition presenting as discrete 2 - to $3-\mathrm{mm}$ papules in skin bearing apocrine glands: axillae, pubic area, perineum and areolae. $\mathrm{Li}-$ chenification and excoriations may be seen, and secondary infections, i.e. impetigo, are common. Rarely has the literature found it to be a familial condition. We herein describe a patient with Fox-Fordyce disease whose father was also affected.

\section{Case Report}

A 17-year-old white female was referred to our clinic for evaluation of a rash in both axillae and pubic area. The lesions were not pruritic or painful. Her primary-care physician had originally diagnosed genital warts and had treated the patient with liquid nitrogen.

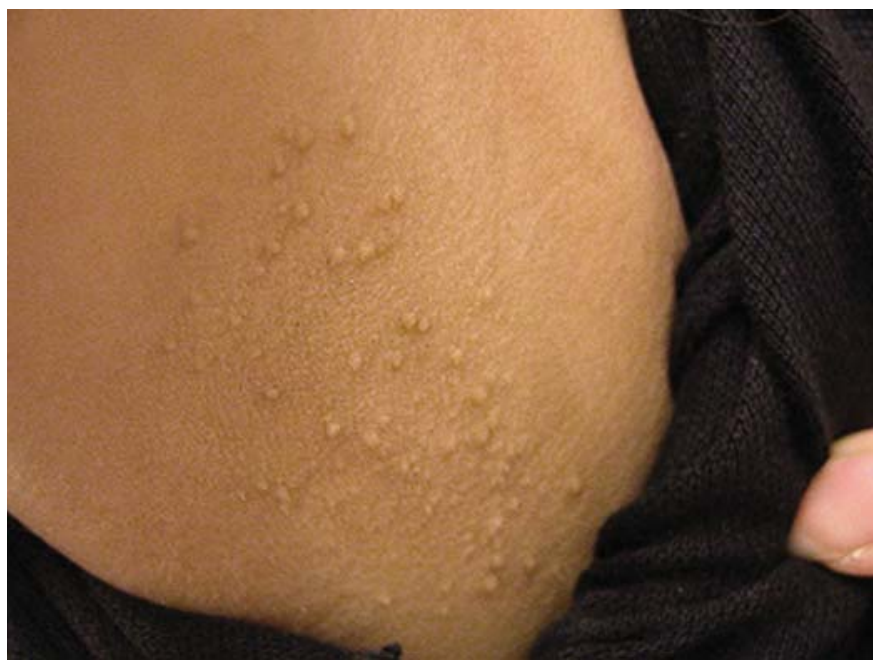

Fig. 1. Perifollicular papules in the axillae.

\section{KARGER}

(C) 2008 S. Karger AG, Basel

Fax +41613061234 E-Mail karger@karger.ch www.karger.com
On examination, discrete 2- to 3-mm perifollicular papules localized to the bilateral axillae (fig. 1) and the pubic area were noted. The color of the papules ranged from flesh-colored to slightly hypopigmented. Additionally, her left axilla showed areas of superficial erosion, erythema and overlying honey-colored crust (fig. 2). Of particular interest, the patient's father was also examined in our office because of a similar eruption in both axillae, which was asymptomatic.

A diagnosis of Fox-Fordyce disease with superficial impetigo was made clinically, and the patient was treated with oral antibiotics and bacitracin ointment. The impetigo improved, but the apocrine miliaria persisted. Since the lesions were asymptomatic, she desired no further treatment.

\section{Discussion}

Fox and Fordyce first described the disease in 1902 [1]. They reported 2 cases - a young woman and a young man who presented with small papular lesions in the axillary region. The papules were numerous, firm, smooth, rounded and of normal color. Both patients experienced intense pruritus that affected their daily life. The histology of the lesions was described as hyperkeratosis involving chiefly the sweat duct orifices and their intraepidermal portions as well as a chronic dermal infiltrate.

In 1956, Shelley and Levy [2] further elaborated the description of Fox and Fordyce. They described it as occurring in the axillae, pubic area, labia, perineum, areolae, presternal area, umbilicus and the medial aspect of the upper thigh. Papules were

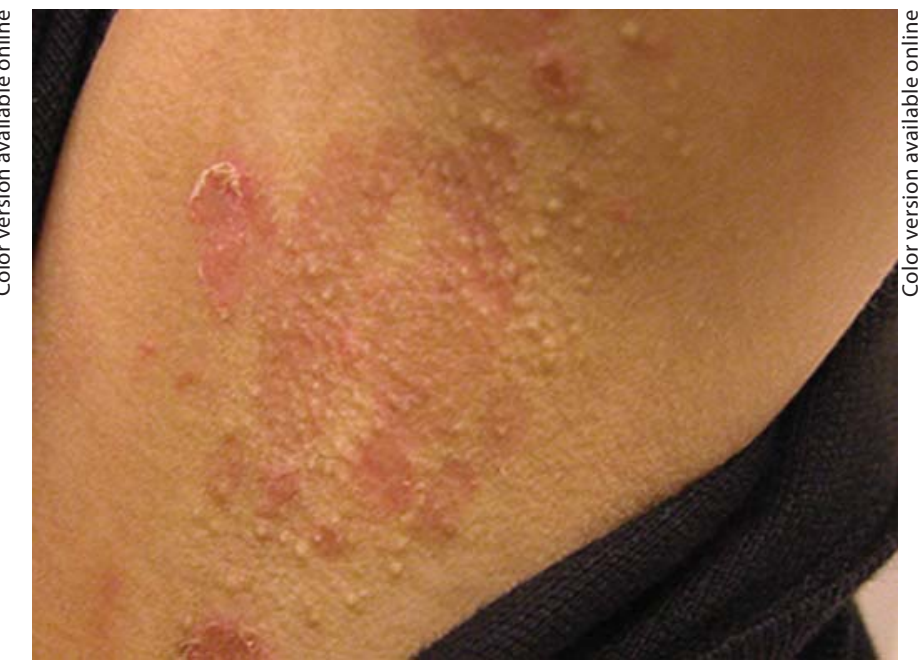

Fig. 2. Superficial erosion, erythema and overlying honey-colored crust. 
described as discrete, flesh colored and perifollicular with a smooth, dome-shaped contour, frequently with a central punctum. It is a disease most common in women between 13 and 35 years of age [2] and rarely seen before puberty [3], although more recent literature believes that the diagnosis is often missed in prepubertal girls [4]. As such, our case was initially misdiagnosed as genital warts.

The pathophysiology consists of a keratin plug in the terminal apocrine duct. This causes the dilatation of the apocrine sweat gland unit, and leads to ductal rupture and formation of an apocrine sweat retention cyst in the epidermis. Thus, an apocrine anhidrosis is noted. Pruritus is thought to be caused by extravasation of sweat [2]. The exact pathogenesis of the disease remains unknown although emotional factors, hormonal influences and chemical changes in the sweat components are all thought to be contributors [5].

Several treatments have been described with varying success. Most recently, pimecrolimus was shown to be successful in 3 young females [6]. Other methods mentioned in the literature include adapalene gel [4], liposuction-assisted curettage [7], topical clindamycin [8], oral retinoids [9], topical tretinoin cream [10,11] topical $5 \%$ benzoyl peroxide combined with loratadine [12], ultraviolet radiation [13] and electrocoagulation [14].

Our patient's father also exhibited classic Fox-Fordyce lesions. Rarely has Fox-Fordyce disease been mentioned as a familial disease, although 2 cases have been reported in sisters [8] and in 14year-old identical male twins [15].

\section{Conclusion}

We present the 3rd case supporting a hereditary component in Fox-Fordyce disease and the first case involving two generations and opposite sexes. We suggest that a genetic component may be involved in the pathogenesis of the disease.

\section{References}

1 Fox GH, Fordyce JA: Two cases of a rare papular disease affecting the axillary region. J Cutan Genitourin Dis 1902;20:1-5.

2 Shelley WB, Levy EJ: Apocrine sweat retention in man, II. Fox-Fordyce disease (apocrine miliaria). Arch Dermatol 1956;73:38.

3 Mevorah B, Duboff GF, Wass RW: Fox-Fordyce disease in prepubescent girls. Dermatologica 1968;136:43-56.

4 Sandhu K, Gupta S, Kanwar AJ: Fox-Fordyce disease in a prepubertal girl. Pediatr Dermatol 2005;22:89-90.

5 Ranalleta M, Rositto A, Drut R: Fox-Fordyce in two prepubertal girls: histopathologic demonstration of eccrine sweat gland involvement. Pediatr Dermatol 1996;13:294-297.

-6 Pock L, Svrckova M, Machackova R, Hercogova J: Pimecrolimus is effective in Fox-Fordyce disease. Int J Dermatol 2006;45:1134-1135.

7 Chae KM, Marschall MA, Marschall SF: Axillary Fox-Fordyce disease treated with liposuction-assisted curettage. Arch Dermatol 2002;138: $452-454$.

$\checkmark 8$ Miller M, Harford RR, Yeager JK: Fox-Fordyce disease treated with topical clindamycin solution. Arch Dermatol 1995;131:1112-1113.

-9 Effendy I, Ossowski B, Happle R: Fox-Fordyce in a male patient: response to oral retinoid treatment. Clin Exp Dermatol 1994;19:67-69.

10 Tkach JR: Tretinoin treatment of Fox-Fordyce disease. Arch Dermatol 1979;115:1285.

11 Giacobetti R, Caro WA, Roenigk HH: Fox-Fordyce: control with tretinoin cream. Arch Dermatol 1979;115:1365-1366.

12 Ozcan A, Senol M, Aydin NE, et al: Fox-Fordyce disease. J Eur Acad Dermatol Venereol 2003;227-249.

13 Pinkus H. Treatment of Fox-Fordyce disease. JAMA 1973;223:924.

14 Pasricha JS, Nayyar KC. Fox-Fordyce in the post-menopausal period treated successfully with electrocoagulation. Dermatologica 1973;147: 271-273.

15 Graham JH, Shafer JC, Helwig EB: Fox-Fordyce disease in male identical twins. Arch Dermatol 1960;82:104-113.

Leslie K. Scroggins

University of Texas Medical Branch

610 13th Street

Galveston, TX 77550 (USA)

Tel. +1 903520 8395, Fax +1 4097721943

E-Maillkscrogg@utmb.edu 